\title{
Um estudo acerca dos contextos emergentes nos cursos de licenciatura no Brasil: em destaque a internacionalização
}

\author{
A study about the contexts emerging in the courses of licenciatura in Brazil: \\ in highlight internationalization
}

\section{Un estudio acerca de los contextos emergentes en los cursos de licenciatura en Brasil: en destaque la internacionalización}

\author{
MARILENe GABRIEl DALla CORTE*
}

\begin{abstract}
RESUMO
Este estudo delineia e analisa os principais elementos que configuram contextos emergentes na Educação Superior e, em especial, nos cursos de licenciatura no Brasil. Trata-se de uma pesquisa do estado do conhecimento, realizada na Biblioteca Digital do Instituto Brasileiro de Informação em Ciência e Tecnologia (IBICT), no período de 2012 a 2016. Os trabalhos analisados apresentam elementos que caracterizam o que tem se configurado emergente na perspectiva da expansão e diversificação, da interlocução educação básica e superior, da diversidade e, em especial, da internacionalização entendida como desafio aos cursos de licenciatura. Nas produções científicas a terminologia "contextos emergentes" ainda é pouco discutida, entretanto estão relacionados a elementos que interferem ou decorrem da [re]formulação de políticas educacionais; se descortinam em estratégias e ações de governo e/ou institucionais e estão imbricados ao cenário da formação de professores.

Palavras-chave: Contextos emergentes. Internacionalização. Cursos de licenciatura. Educação Superior.
\end{abstract}

\begin{abstract}
This study outlines and analyzes the main elements that configure emerging contexts in Higher Education and, in particular, undergraduate courses in Brazil. It is a research of the state of knowledge, carried out in the Digital Library of the Brazilian Institute of Information in Science and Technology (IBICT), from the period of 2012 to 2016. The papers analyzed present elements that characterize what has emerged from the perspective the expansion and diversification, the dialogue between basic and higher education, diversity and, in particular, internationalization understood as a challenge to undergraduate courses. In scientific productions the terminology "emergent contexts" is still little discussed, however they are related to elements that interfere or result from the [re]formulation of educational policies; are unveiled in government and/or institutional strategies and actions and are embedded in the scenario of teacher training.
\end{abstract}

Keywords: Emerging contexts. Internationalization. Degree courses. College Education.

\section{RESUMEN}

Este estudio delinea y analiza los principales elementos que configuran contextos emergentes en la Educación Superior $\mathrm{y}$, en especial, en los cursos de licenciatura en Brasil. Se trata de una investigación del estado del conocimiento, realizada en la Biblioteca Digital del Instituto Brasileño de Información en Ciencia y Tecnología (IBICT), en el período de 2012 a 2016. Los trabajos analizados presentan elementos que caracterizan lo que se ha configurado emergente en la perspectiva de la expansión y diversificación, de la interlocución educación básica y superior, de la diversidad y, en especial, de la internacionalización entendida como desafío a los cursos de licenciatura. En las producciones científicas la terminología "contextos emergentes" todavía es poco discutida, sin embargo están relacionados a elementos que interfieren o derivan de la [re]formulación de políticas educativas; se descortinan en estrategias y acciones de gobierno y/o institucionales y están imbricados al escenario de la formación de profesores. Palabras clave: Contextos emergentes. Internacionalización. Cursos de licenciatura. Educación Universitaria.

\footnotetext{
* Doutora em Educação - PUCRS; Mestre em Educação - UFSM; Especialista em Administração e Supervisão Escolar - UFSM; Especialista em Psicopedagogia - FAFRA; Graduada em Pedagogia - FIC. Bolsista CNPq PDJ, cursando Pós-Doutorado na Pontifícia Universidade Católica do Rio Grande do Sul, com o foco na temática Educação Superior e Contextos Emergentes. Professora Adjunta do Departamento de Administração Escolar - ADE, do Centro de Educação da Universidade Federal de Santa Maria - UFSM. Coordenadora Substituta e docente no Programa de Pós-Graduação em Políticas Públicas e Gestão Educacional (PPPG) do Centro de Educação da Universidade Federal de Santa Maria. Integrante do Conselho Municipal de Educação de Santa Maria/RS - CMESM. Líder do GESTAR - Grupo de Estudos e Pesquisas em Políticas Públicas e Gestão Educacional. Vice-líder do Grupo de Estudos e Pesquisa ELOS. Integrante do Grupo de Pesquisa UNIVERSITAS/RIES. E-mail: <marilenedallacorte@gmail.com>.
} 


\section{INTRODUÇÃO}

A universidade do século XXI tem sido considerada lócus privilegiado de produção do conhecimento e, devido aos desafios e as transformações da sociedade do conhecimento, torna-se necessário, cada vez mais, [re] configurar os tempos, os espaços e as práticas de gestão universitária como elementos essenciais na produção de novos conceitos e cultura organizacional da própria existência e funcionalidade da universidade para a formação profissional de qualidade.

Nessa perspectiva, as transformações que acontecem no contexto das Instituições de Educação Superior (IES), aparentemente, são internas, porém, possuem interrelação com as demandas sociais, culturais, econômicas, entre outras, que implicam no surgimento de uma nova arquitetura para a Educação Superior e, consequentemente, atuais demandas para a universidade que, influencia e se deixa influenciar pelas políticas públicas educacionais globais e locais. Essa realidade multifacetada passou denominar-se contexto emergente e requer uma nova pedagogia universitária que se ancora num ambiente de mudança e tensionamentos. Considera-se que:

[...] os desafios para a gestão do Ensino Superior passam por significativas mudanças no Ensino Superior: surgimento de novos "fornecedores" de cursos de / emergência de novas instituições de ensino póssecundário; novas formas de ensino (ensino virtual, educação a distância); competição para a obtenção de financiamentos públicos e de outras fontes de receita; uma mudança no perfil da população estudantil existente e a emergente. (CERDEIRA, 2012, p. 96)

Também, parte-se do pressuposto que:

[...] é preciso considerar as pressões para as mudanças e as direções apontadas para elas quando se discute o papel esperado da universidade. A universidade não deve simplesmente adequar-se às oscilações do mercado, mas aprender a olhar em seu entorno, a compreender e assimilar os fenômenos, a produzir respostas às mudanças sociais, a preparar globalmente os estudantes para as complexidades que se avizinham, e situar-se como instituição líder, produtora de ideias, culturas, artes e técnicas renovadas que se comprometam com a humanidade, com o processo de humanização. (PIMENTA E ANASTASIOU, 2010, p. 173).

Então, na conjuntura dos "contextos emergentes", as "mudanças", as "novas direções", os "novos desafios" se constituem em "novas exigências", em "novas realidades", em "novas formas de fazer"? No que diz respeito a Educação Superior e, consequentemente, as IES, sendo que esta lógica que se configura em nível mundial, seja por meio da realização de conferências, tratados, pesquisas e delineamento de rankings, acordos de cooperação, mobilidades e intercâmbios, planejamento e consecução de projetos em cooperação técnica em contexto interregional, internacional e/ou institucional, entre outros, decorre de ou decorre em algo "novo" no cenário das políticas e, consequentemente, das instituições sociais e educacionais. Ou seja, a dinamicidade vivida na sociedade da "Era Tecnológica" se agrega às transformações e desafios da "Sociedade do Conhecimento", conforme aborda Motta (2013, p. 117):

[...] As transformações na forma de aprender e ensinar sofreram interferências significativas destas que todos chamam de "Era Tecnológica" e "Sociedade do Conhecimento", em que as informações chegam de forma quase instantânea, no mesmo momento em que acontecem, e isso traz à tona a necessidade de reflexão sobre um novo atuar nesse cenário tão dinâmico, cuja questão do saber dos educadores e os métodos de ensino tradicionais são colocados à prova. A informação se torna mutante, e a reciclagem e a aquisição do saber, contínuas, em um ciclo de construção e reconstrução do conhecimento nunca visto antes.

Para tanto, uma realidade multifacetada que emerge e culmina no rápido acesso à informação e em novos modos de organização institucional e societal, ancorada nos preceitos da globalização, mas que requer quase que cotidianamente que as instituições de [re]dimensionem, novos ambientes educativos, novas práticas pedagógicas e, neste sentido, inovações educacionais ancoradas em [re]configurações e [re]articulações dos/nos processos de gestão e de ensino-aprendizagem.

Sendo assim, os estudos oriundos do projeto de pesquisa intitulado "Impactos das políticas de formação de professores em contextos emergentes", desenvolvido no contexto do Centro de Estudos em Educação Superior (CEES) da Pontifícia Universidade Católica do Rio Grande do Sul (PUCRS), do Grupo de Pesquisa Universitas/CNPq e do Grupo de Estudos e Pesquisas em Políticas Públicas e Gestão Educacional - GESTAR/CNPq, tem neste paper o objetivo de delinear e analisar os principais elementos que configuram contextos emergentes na Educação Superior e, em especial, nos cursos de licenciatura no Brasil.

A metodologia está embasada em uma pesquisa do estado de conhecimento (MOROSINI, 2015), no sentido de revisão de literatura com aprofundamentos de leitura e estudos em produções científicas junto a Biblioteca Digital Brasileira de Teses e Dissertações (BDTD) do Instituto Brasileiro de Informação em Ciência e Tecnologia (IBICT), no período de 2012 a 2016. O estado do conhecimento configura-se uma pesquisa que, segundo 
Ferreira (2002), prioriza mapear e discutir produções acadêmicas em diferentes campos do conhecimento, tentando responder que aspectos vem sendo abordados e destacados em múltiplos tempos e espaços, bem como de que maneira e em que condições tem sido produzida e socializada tais produções científicas. Assim, buscouse priorizar na seleção, leitura flutuante e categorização das tendências e contribuições dos estudos referentes a configuração dos contextos emergentes na Educação Superior, em especial nos cursos de licenciatura no Brasil.

Este texto se organiza em momentos que estão interrelacionados. Após a introdução, em que se apresenta o objeto de estudo, procedimentos metodológicos gerais e demais conexões, adentra-se na fundamentação de contextos emergentes e caracterização dos mesmos no cenário da Educação Superior, com ênfase à internacionalização. Subsequentemente, apresenta-se o universo teórico-metodológico utilizado para a realização da pesquisa, bem como explora-se os principais elementos que configuram contextos emergentes na Educação Superior e nos cursos de licenciatura no Brasil. Prioriza-se trabalhar com dados qualitativos imbricados a concepções e [re]formulações das políticas públicas educacionais à formação de professores. Por fim, apresenta-se as [in] conclusões a título de considerações em construção do conceito relacionado aos contextos emergentes nas licenciaturas.

\section{CONTEXTOS EMERGENTES NA EDUCAÇÃO SUPERIOR}

Estamos acompanhando cotidianamente novas formas de pensar e agir em sociedade, o que requer aos sujeitos sociais, históricos e culturais a busca por [re] configurações e atualizações nas maneiras de [con]viver e produzir em sociedade. Tais buscas incidem em aprender a [con]viver como um emaranhado de informações e tecnologias que exigem uma cultura organizacional diferenciada no que diz respeito a compreensão e ao uso de ferramentas digitais e softwares avançados, os quais contém novas formas e exigências de manuseio, além de múltiplas possibilidades de interlocução e produção técnica e científica. Tais desafios a partir de novos formatos em inter-relações com políticas sociais constituem-se contextos emergentes.

O mundo se acelera, o avanço frenético das descobertas cientificas impulsiona a produção e o consumo de novas formas de vida, permeadas pelas tecnologias. Novos avanços em pesquisas relativizam os conhecimentos anteriores. Tudo se torna descartável, passível de ser superado rapidamente. Prevalece a lógica do efêmero, do pontual. 'Aqui e agora' é a forma de percepção da vida e do mundo. É a forma expressa da compreensão da realidade como fusão espaço temporal. [...] $\mathrm{O}$ acesso e o uso da internet, da televisão e de todos os tipos de dispositivos móveis de comunicação estão distribuídos por toda a parte e disponíveis a todo momento (KENSKI, 2013, p. 27-28).

Esses elementos, conforme retrata Kenski acerca das tecnologias, são subjacentes aos aspectos evolutivos da humanidade e, nesta lógica, agregam culturas organizacionais balizadas por campos conceituais, dinâmicas sociais e institucionais, assim como marcos normativos delineados por legislações pertinentes as respectivas áreas e setores que compõem a sociedade.

$\mathrm{Na}$ educação superior não é diferente, já que tais elementos entre outros estão no bojo do cenário das instituições em nível global e possuem inter-relações com as demandas e desafios conectados às dinâmicas sócio educacionais de formação e atuação para/no mundo do trabalho. Neste sentido, compreender a abrangência e a dinâmica de contextos emergentes torna-se desafiador aos profissionais da educação. Para tanto, busca-se destacar alguns elementos conceituais que caracterizam, especialmente, as múltiplas arquiteturas formativas e as estratégias de governo e institucionais que tem produzido novos formatos institucionais e processos de gestão decorrentes no cenário da educação superior no Brasil nas últimas décadas.

Morosini (2014, p. 386), salienta que “[...] além de desafios às funções de ensino, pesquisa e extensão de qualidade, novos desafios estão postos dos quais se destaca considerar as demandas locais num contexto global". Para tanto, é importante compreender quais sejam os "novos desafios" ou, até mesmo, àqueles que se constituem em atualizações e [re]configurações no contexto das Instituições de Ensino Superior (IES), e quais incidem diretamente na [re]formulação de políticas públicas educacionais voltadas à formação de professores.

No Brasil, um contexto emergente evidenciado, a exemplo da América Latina, é o da expansão acelerada, além das políticas de diversificação e privatização, marcadas por tendências democratizantes, comandadas pela centralização estatal. Ainda, dispomos de uma Educação Superior de elite, mas com novos formatos de Instituições de Ensino Superior, que vem sendo, aos poucos constituídas por novos docentes, discentes, currículos, pois as exigências da sociedade, do mercado e da globalização também são novas com relação à educação superior.

No que se refere aos cursos de licenciatura, na conjuntura da Educação Superior brasileira, são muitas as demandas que estão imbricadas a contextos emergentes, entre elas, destaca-se a globalização, a 
cibercultura, a expansão e diversificação das IES, a inclusão e a diversidade, a educação a distância pela Universidade Aberta do Brasil, os programas de governo, a internacionalização, entre outros. A maioria destes elementos não são novos no cenário das IES, porém, cotidianamente, produzem novos sentidos, precisam de novas [re]articulações e dinamizações que estão imbricadas às [re]formulações das políticas públicas globais e locais, bem como estão relacionados à concepção híbrida de gestão educacional do governo brasileiro que, ao mesmo tempo que autoriza as instituições a assumirem sua governança e se constituírem partícipes nos processos de gestão, é um governo gerencialista que centraliza decisões tais como quais projetos e programas poderão ser implementados, qual a fonte de recursos e quando e como serão repassados tais recursos, entre outros aspectos que são elementares para os processos de democratização educacional.

Franco e Morosini (2012, p. 189-181), realizam uma análise que delineia as configurações dos contextos emergentes nas IES:

[...] o movimento expansionista no contexto pósLDB/1996 e seus desdobramentos se, por um lado, veio em resposta a demandas pelo acesso à educação superior, por outro, deixou o sistema mais complexo na medida em que as leituras e análises sobre as novas modalidades, gestaram interpretações e críticas de sua força privatizadora do público e também da publicização do particular. Foram mudanças significativas na base organizativa - princípio da diversificação (formatos, cursos, modalidades terminais, diplomas e certificados), proliferação de ofertas de cursos e programas nas diferentes modalidades a distância, semipresenciais, bem como de cursos superiores tecnólogos; também não se pode omitir que houve um incremento da diversificação e da diferenciação (formatos e modalidades na organização institucional e acadêmica, articulação às tendências internacionais).

Para além das características presentes do que venha a se constituir emergente no cenário das IES brasileiras, as autoras afirmam que as tendências democratizantes permeiam e fundam novas lógicas de gestão universitária, porém sob a égide do gerencialismo estatal. Tal processo de "osmose" entre a governança e o gerencialismo acaba por desencadear uma concepção de gestão híbrida, na lógica de que para as decisões e comprometimento com a consecução dos programas, projetos e ações de ensino, pesquisa e extensão, as universidades possuem autonomia para decidir e se engajar coletivamente e participativamente, porém para decidir quanto ao financiamento e prazos, por exemplo, quem decide de maneira verticalizada é o governo. Neste exemplo, verifica-se a distância entre os processos de planejamento e execução, o que, diretamente, compromete os processos de gestão e, certamente, nos resultados esperados.

$\mathrm{O}$ que se verifica é um contexto engendrado de múltiplas incoerências entre as relações público e privado, entre gestão democrática e preceitos da lógica neoliberal e da globalização, problemáticas sociais e educacionais vinculadas as metas estabelecidas pelos organismos internacionais e que estão relacionadas as opções e [re]formulação das políticas públicas e ações políticopedagógicas institucionais. Nessa conjuntura, as IES são desafiadas a compreender a lógica mundial/nacional/local e oportunizar espaços de discussão, estudo e interação entre sujeitos, estudos de marcos legais e teóricos, estudo e análises de indicadores e de fatores intervenientes à atuação docente na sociedade do conhecimento e que produz e é produzida por contextos emergentes. Uma lógica dual e perversa, pois responsabiliza a base da pirâmide, a mesma base que na maioria das vezes não tem ingerência sobre as regras do jogo e está, constantemente, a serviço de poucos que decidem o que é mais rentável para o desenvolvimento econômico do país.

\section{O QUE DIZEM AS PRODUÇÕES CIENTÍFICAS ACERCA DOS CONTEXTOS EMERGENTES NOS CURSOS DE LICENCIATURA NO BRASIL?}

Para delinear e analisar os principais contextos emergentes que se configuram nos cursos de licenciatura no Brasil, adotou-se os princípios do estado do conhecimento considerando o que sinalizam teses e dissertações disponíveis do banco de dados do Instituto Brasileiro de Informação em Ciência e Tecnologia (IBICT), mais especificamente na Biblioteca Digital Brasileira de Teses e Dissertações, disponível em <http:// bdtd.ibict.br/vufind/>.

O estado do conhecimento constitui-se pelo acesso ao conhecimento já produzido com base em conceitos e princípios que balizam as temáticas de pesquisa. Para Morosini e Fernandes (2014, p. 155) o estado de conhecimento "[...] é identificação, registro, categorização que levem à reflexão e síntese sobre a produção cientifica de uma determinada área, em um determinado espaço de tempo, congregando periódicos, teses, dissertações e livros sobre uma temática específica".

Esta pesquisa priorizou etapas subsequentes voltadas para o reconhecimento, o delineamento e a interpretação do conhecimento produzido nas teses e dissertações dos últimos cinco anos. Assim sendo, buscou-se na etapa inicial realizar um estudo exploratório para selecionar os resumos das teses e dissertações disponíveis no banco de dados do IBICT quanto a temática de pesquisa; após desenvolveu-se leitura flutuante para o reconhecimento nos resumos das principais categorias. Na segunda etapa, 
buscou-se realizar leitura em maior profundidade, de natureza qualitativa, com finalidade de selecionar os trabalhos adequados ao estudo com a compilação de dados subjacentes. Por fim, na terceira etapa, investiuse na produção de texto priorizando o delineamento dos contextos emergentes que configuram o cenário dos cursos de licenciatura no Brasil e o entrecruzamento dos dados compilados. Nesta etapa, aprofundou-se a leitura de alguns textos que tiveram seus resumos selecionados e passou-se às análises dos mesmos.

Na tabela a seguir, é possível identificar o número de dissertações e teses, encontradas por categoria delineada na segunda etapa deste estudo:

Tabela 1. Quantitativo de Dissertações e Teses encontradas na pesquisa

\begin{tabular}{lcc}
\hline Categorias & Dissertações & Teses \\
\hline Diversidade & 65 & 27 \\
Expansão & 21 & 18 \\
Internacionalização & 43 & 32 \\
Interlocução Educação Básica e Superior & 32 & 15 \\
Total & 161 & 92 \\
\hline
\end{tabular}

Fonte: Produzida pela autora. Repositório da Biblioteca Digital Brasileira de Teses e Dissertações, disponível em: <http://bdtd.ibict.br/vufind/> no período de 2012 a 2016).

Na Figura 1 acerca da categorização e quantitativos dos trabalhos selecionados no período de 2012 a 2016, na terceira etapa deste estudo, priorizou-se a interlocução das discussões do cenário da Educação Superior e dos cursos de licenciatura no Brasil:

Figura 1. Categorias e quantitativo dos trabalhos selecionados no período 2012 a 2016

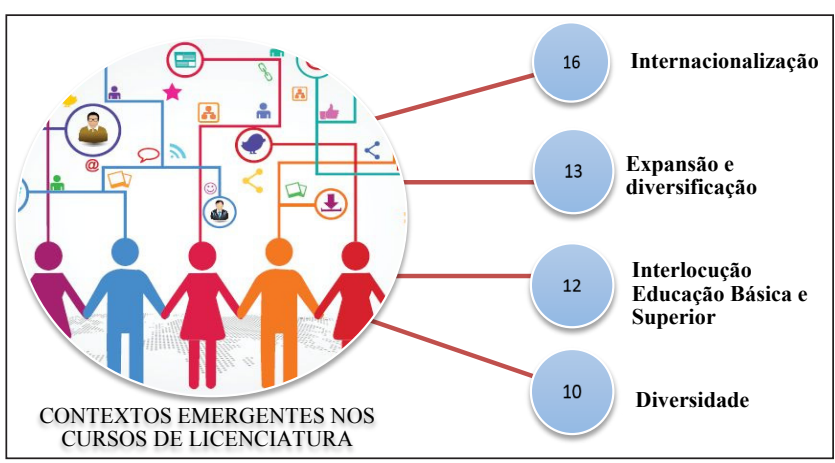

Fonte: Produzida pela autora. Repositório da Biblioteca Digital Brasileira de Teses e Dissertações, disponível em: <http://bdtd.ibict.br/vufind/>, no período de 2012 a 2016.

No contexto da pesquisa, temos os lócus do estudo centrado nos cursos de licenciatura. Sendo assim, se fez necessário que as categorias elencadas para a pesquisa do estado do conhecimento estivessem alinhadas com questões relacionadas a constituição de políticas públicas para a Educação Superior, em especial os cursos de licenciatura no Brasil, e o que se constitui emergente neste cenário. Optou-se, considerando o vasto conteúdo encontrado nas produções científicas, apresentar os resultados e análises mais gerais acerca das categorias interlocução Educação Básica e Superior, expansão e diversificação, diversidade; e, por fim, em maior profundidade, a categoria a internacionalização explorada como um contexto emergente desafiador e dual.

Nos trabalhos acerca da “interlocução Educação Básica e Superior", identificou-se como emergente: a oferta de cursos de licenciatura a distância e a discussão quanto a primeira ou a segunda licenciatura para professores que estão atuando na Educação Básica ou, por vezes, não possuírem formação superior e/ou estarem atuando em desvio de função sem a devida formação; a influência dos organismos multilaterais na [re]formulação de políticas de formação de professores; o desenvolvimento de programas de governo que estabelecem conexão dos cursos de licenciatura com as escolas de Educação Básica.

Destaca-se que os trabalhos encontrados com temática relacionada a oferta de cursos de licenciatura a distância, apresentam discussões acerca do desenvolvimento profissional docente na Educação Básica, tanto sob a perspectiva dos formadores como sob o olhar dos estudantes que, muitos, já são professores em serviço. Apontam o advento das tecnologias digitais e ambientes virtuais como um desafio aos formadores e estudantes; da importância das tecnologias digitais de informação e comunicação articuladas com os estruturantes didáticos na educação a distância; a evasão como uma dificuldade encontrada na formação a distância. Além de suas especificidades, as temáticas relacionadas a educação a distância, abordam como fator comum de sua argumentação e emergente, a inclusão digital no contexto da formação de professores. Esta é designada como uma ferramenta fundamental na perspectiva de [re]significar a estrutura curricular de cursos a distância, principalmente de licenciatura (SILVA, 2013; PINHEIRO, 2012; CAVALCANTI, 2014).

Quanto a influência dos organismos multilaterais na [re]formulação de políticas de formação de professores, no bojo dos trabalhos encontra-se elementos teóricos com discussões acerca da inter-relação e influência dos organismos na [re]formulação de políticas para a formação de professores; diz respeito as orientações de tais órgãos internacionais quanto ao necessário diálogo e trabalho conjunto entre Educação Superior e Básica. Esta lógica, para as organizações internacionais está bem delineada nos relatórios síntese que analisam o cenário da Educação Básica e Superior em nível mundial, bem como nos textos decorrentes das prioridades e compromisso assumidos pelos países que participaram das Conferências 
Mundiais de Educação desde 1990 até os dias atuais (FRANCO, 2015).

$\mathrm{O}$ desenvolvimento de programas de governo a exemplo do Programa Institucional de Bolsa de Iniciação à Docência (PIBID), podem ser identificados a partir das produções que destacam, respectivamente, os desafios e as potencialidades das universidades públicas de pautar sua ação política e pedagógica conforme as exigências da atual política educacional para a Educação Superior e analisam a relação desta com a Educação Básica a partir do êxito e das fragilidades dos processos formativos na academia e no contexto escolar. Apontam o PIBID como um Programa que potencializa a aproximação e interdependência entre escola e universidade, a sensibilização dos professores em serviço na Educação Básica para a necessidade de investimento permanente em sua formação, as melhorias nos processos de gestão pedagógica nas escolas e a necessidade da academia conhecer melhor os lócus de atuação docente para potencializar práticas político-pedagógicas adequada a estes contextos (DALLA NORA, 2015; JAHN, 2015; VICENTE, 2016; COSTA, 2011; CAMATTI, 2011).

Os trabalhos vinculados à categoria de análise “expansão e diversificação" apresentam temáticas como: políticas de expansão do Ensino Superior no contexto da reforma da Universidade, via Plano de Reestruturação e Expansão das Universidades Federais (REUNI), e as consequências desta expansão; multicampis com estruturas diferenciadas; criação e ampliação de Institutos Tecnológicos; cursos e polos na modalidade a distância. Também, aparecem as contribuições do Plano Nacional de Formação de Professores da Educação Básica (PARFOR) com acelerada expansão de matrículas em cursos de graduação em licenciatura (NASCIMENTO, 2012; MACIEL, 2014).

Em Lima (2015), encontra-se análise detalhada acerca do crescimento dos Institutos Tecnológicos no Brasil, a partir da inter-relação entre políticas públicas e a criação dos Institutos Federais, por meio do Plano de Expansão que implantou os Institutos Federais de Educação, Ciência e Tecnologia (IFs) em todo o território brasileiro.

Além disso, com expansão na Educação Profissional e Superior, verificou-se a emergente e substancial oferta de cursos de licenciaturas nos Institutos Federais e que as origens sociais dos estudantes deste cenário formativo revela baixas credenciais quanto ao capital cultural e socioeconômico, o que requer as estas instituições de educação profissional e seus formadores a busca de [re] articulações curriculares, bem como de gestão políticopedagógica para atender a demanda de formação profissional na seara das licenciaturas (LORENZET, 2016).

A categoria intitulada "diversidade", é referente aos trabalhos com temáticas direcionadas à ações de acesso e permanência, ações afirmativas, políticas sociais, sistema de cotas, questão étnico-raciais, gênero, direitos humanos, camadas sociais subalternizadas e desigualdades educacionais, direito de igualdade, interculturalidade, novíssimos movimentos sociais, acessibilidade, modalidades educacionais, Tecnologias da Informação e Comunicação, entre outros (PINTO, 2015; STOLF, 2014; TANAKA, 2013; BARRETO, 2015).

Verificou-se que as produções que tratam das políticas de acesso sinalizam que estas cumprem um papel primordial, mas elas se fragilizam após o ingresso do estudante na universidade, na medida em que muitos deixam de frequentar o curso superior. Nesse sentido, as políticas de acesso precisam ser concebidas e apoiadas por políticas de permanência.

Sobre as políticas de permanência evidenciou-se que é crescente o número de estudantes em situação de vulnerabilidade socioeconômica nas universidades. A assistência estudantil é um campo em disputa que, por um lado, se tem a defesa de bolsas e auxílios para estudantes em situação socioeconômica vulnerável e, por outro, a luta do movimento estudantil em busca de políticas de permanência de caráter universal. As atuais políticas de assistência estudantil da universidade no Brasil, ainda, tem necessidade de se reestruturar visando garantir os direitos de uma permanência sustentável a todos os estudantes, ou seja, a ausência de políticas de permanência pode colaborar para elevação dos índices de evasão, de retenção e o baixo índice de concluintes. Os trabalhos encontrados sugerem que as políticas de universalização do acesso e de inclusão no ensino superior de estudantes, provenientes, em sua maioria, de extratos socioeconômicos médio-baixos, venham acompanhadas de políticas de permanência voltadas à ampliação da oferta de oportunidades de realização de atividades remuneradas de pesquisa, estágio e extensão na própria área do curso, bem como na instituição de políticas de apoio e de acompanhamento aos estudantes.

Outra evidência nas produções, se refere as políticas afirmativas, entre elas as cotas. Os núcleos e os movimentos sociais internos colaboram para que as ações afirmativas se efetivem nas IES, porém, verificou-se nos dados produzidos nos textos analisados que há falta de politização nos argumentos trazidos pelos estudantes para explicar o que é, por exemplo, ser negro e ser cotista. Esse embate traz consigo a necessidade de discutir coletivamente no âmbito interno e externo da comunidade acadêmica sobre o preconceito racial, as dificuldades de manter-se no Ensino Superior, a necessidade de conciliar trabalho e estudo devido aos gastos com moradia, alimentação e transporte, a falta de apoio pedagógico e a insuficiência de bolsas. Em alguns estudos, consta que nas IES a questão do reconhecimento é abordada 
de forma superficial pela instituição, não sendo levadas em conta as particularidades e individualidades dos sujeitos que a integram. Esses fatores refletem de forma negativa na formação dos futuros professores, pois a falta de reconhecimento tem influência na construção da identidade e realização profissional do docente independente da área de atuação.

A modalidade a distância também é recorrente nesta categoria de análise e, neste sentido, identificouse que não se constitui por si mesma uma ferramenta de redistribuição e justiça social, uma vez que pode ser facilitadora nos processos de inclusão na Educação Superior. Como estratégia de acesso e acessibilidade, as IES tem utilizado a educação a distância (EaD) que, por exemplo, se traduz na organização de iniciativas de produção de recursos pedagógicos adaptados, ainda que seja em pequena escala, para o acompanhamento da trajetória de formação e da aprendizagem dos alunos com deficiências, transtorno global do desenvolvimento e altas habilidades/superdotação matriculados em algumas universidades. Está pontual, na maioria dos textos selecionados, que a EaD, enquanto política pública educacional, vem contribuindo para o acesso à Educação Superior pelas pessoas que vivem em lugares distantes dos grandes centros e para a capacitação de professores da Educação Básica. O conceito de inclusão digital supera o acesso às tecnologias e está relacionado ao empoderamento do sujeito para a transformação da sua realidade e, a educação a distância, tem o potencial de oportunizar aos seus educandos a apropriação das tecnologias digitais de rede e, por conseguinte, a vivência de processos de inclusão digital.

\section{A INTERNACIONALIZAÇÃo DA EDUCAÇÃo SUPERIOR: INTENSÕES E TENSÕES}

Considerando os 18 trabalhos selecionados para análise nesta categoria, pontua-se as recorrências e relevâncias nos textos, destacando o que configura contexto emergente nos cursos de licenciatura na perspectiva da internacionalização em suas concepções, intensões e tensões. Os trabalhos, em sua maioria, abordam:

a) mobilidade acadêmica retratada nos processos de intercâmbio estudantil, migração de estudantes, desenvolvimento de programas de mobilidade a exemplo do Programa ESCALA/AUGM e do Programa Ciência sem Fronteiras, desenvolvimento de acordos de cooperação internacional entre países do hemisfério sul e a integração regional;

b) estratégias de gestão institucional considerando o destino de vagas a estudantes estrangeiros e ao quadro de professores visitantes, a implementação de Programas de Estudantes-Convênio de
Graduação (PEC-G) ou Pós-graduação (PEC$\mathrm{PG}$, estratégias de qualificação do Programa Ciência sem Fronteiras, o planejamento de ações de acolhimento e integração dos estudantes estrangeiros visando uma permanência qualificada, a criação de assessoria ou escritório internacional para estabelecer convênios e contratos com outras universidades, lançamentos de editais e seleção dos alunos que irão estudar no estrangeiro, validação dos diplomas e o reconhecimento dos estudos no exterior, estratégias de mobilidade acadêmica;

c) constituição de redes de trabalho e acordos de cooperação, o que demonstra um movimento ainda tímido nos cursos de licenciatura quanto à pesquisa e à produção do conhecimento compartilhado transpondo fronteiras, para além da mobilidade, via programas de cooperação acadêmica internacional e formação de núcleos de pesquisa de excelência;

Em sua maioria, os trabalhos relacionados à internacionalização debatem a sociedade globalizada e a decorrente diversidade de dilemas provocados por este fenômeno, em especial tencionam a [re]formulação de políticas públicas a serviço do desenvolvimento dos países na lógica do global norte. Neste sentido, percebe-se nos resultados das pesquisas que a [re]definição do conceito de Estado-nação vem desencadeando emergentes desafios às universidades e respectivos cursos de licenciatura. Estes desafios estão direcionados à necessidade dos cursos repensar e trabalhar o conceito de cidadania de maneira multicultural e, nesta lógica, redimensionar o currículo para além das fronteiras nacionais (MONTEIRO, 2013).

Em geral, tais textos abordam a importância e a perspectiva da produção do conhecimento compartilhado, e de como esse processo é relevante para a formação de professores pesquisadores que se inserem em programas e formação de redes de pesquisa internacionais para construir e trocar conhecimentos/experiências. Além disso, encontrou-se estudos comparados entre Brasil e outros países, em especial olhar no hemisfério sul, que tem o foco na mobilidade acadêmica ou ações de intercambio; todos demonstrando que a internacionalização contribui, sobretudo, com o conhecimento e aprimoramento da língua estrangeira, bem como para vivências pessoais e interculturais.

Em algumas das pesquisas encontradas foram analisadas as diretrizes internacionais e nacionais, com a tabulação de dados que se referem a mobilidade, inclusive do Programa Ciência sem Fronteiras, e foi possível perceber as diretrizes internacionais e nacionais a partir dos relatos realizados por alunos e orientadores das contribuições adquiridas por meio da mobilidade estudantil no exterior. É pontual que a internacionalização no contexto dos cursos de licenciatura no Brasil, mesmo 
pelo advento do Programa Ciência sem Fronteiras, é recente, é tímida, constitui-se desafiadora especialmente no que diz respeito ao domínio de línguas estrangeiras, seja pelos docentes quanto pelos discentes, e a pouca utilização das mesmas no desenvolvimento em processos formativos na graduação.

Está constatado que a mobilidade acadêmica constitui centralidade nos processos de internacionalização da Educação Superior, segundo os textos que trazem esta temática de pesquisa, especialmente para os países do global sul, e o Brasil não é exceção neste lócus. Encontra-se o tradicional programa de mobilidade Programa Estudante Convênio (PEC) do Ministério da Educação e do Ministério das Relações Exteriores - com alunos latino-americanos motivados em fixar residência e trabalhar no Brasil; estudantes africanos na busca por um ensino de qualidade como parte de um projeto de vida voltado para promover o desenvolvimento de seu país; acordo de cooperação educacional pelo Programa Estudante Convênio de Graduação (PEC-G) sendo importante para os países em desenvolvimento que dele participam, mais especificamente os Países Africanos de Língua Oficial Portuguesa (PALOP); a perspectiva da integração regional latino-americana, Mercosulina, caracterizada pelo Programa ESCALA/AUGM para ampliar a formação de graduação contribuindo com a criação de um novo olhar sobre a América Latina e suas universidades (FEIJÓ, 2013; SOUSA, 2015; COSTA, 2014).

Elementos importantes, que são considerados emergentes no bojo dos textos analisados, encontram-se nas concepções da cooperação pautada pela solidariedade entre os países. Contudo, é importante ter consciência que a dimensão internacional, no caminho para responder aos desafios propostos ao mundo globalizado, ou talvez pós-globalizado, possa atender ao desenvolvimento das nações considerando as implicações de um modelo de descolonização em nível global. Porém, ainda, o contexto global está fortemente pautado pela racionalidade hegemônica dos países do hemisfério norte e, neste sentido, tal ideologia está imbricada no direcionamento do que se constitui prioritário, inclusive, na formação e atuação de professores e, portanto, na [re]formulação de políticas educacionais.

Para tanto, alguns trabalhos apontam evidências relativas ao envolvimento dos pesquisadores em estudo e construção compartilhada do conhecimento pela formação de redes regionais, [inter]continentais que aproximam centros de ensino e de pesquisa, com a finalidade de produzir conhecimento científico e tecnológico, colocando as comunidades científicas de diferentes partes do planeta mais próximas e comprometidas com a construção e difusão do conhecimento (CUNHA, 2016; SILVA, 2012; SENA, 2013; VILALTA; 2012).
Considerando os discursos e movimentos de cooperação internacional, fundamentados pelo necessário desenvolvimento dos países e pela produção qualificada do conhecimento, há implicações que devem ser consideradas, uma vez que a internacionalização da Educação Superior se constitui fértil mecanismo de alargamento das relações transfronteiriças e de integração regional. Um mecanismo que pode fortalecer laços de produção conjunta e solidária do conhecimento ou de disseminação ideológica de "disfarçada integração" que está atrelada à égide das orientações dos organismos multilaterais e do capital mundial, por exemplo.

Destarte, é importante que a internacionalização da Educação Superior seja realizada de maneira responsável, criteriosa e com a perspectiva de complementar a dimensão local (KNIGHT, 2012), pela articulação entre instituições e países em integração não subordinada. $\mathrm{Na}$ ótica emergente, encontrou-se fundamento nos estudos que debatem uma realidade mundial ancorada na "ecologia de saberes", com concepções e valoração das múltiplas culturas, das diferenças, do tempo e da produção, entre outros elementos importantes, como um conjunto de epistemologias capazes de desconstruir o "colonialismo" ainda muito presente nas relações dos países do norte com os países do sul. Os pesquisadores ancoram-se na concepção de horizontalidade entre os países do sul como uma estratégia de internacionalização recente, em contraposição a verticalidade ideológica e hegemônica da relação norte - sul (SENA, 2013; TAVARES, 2016).

Pelos caminhos da internacionalização da Educação Superior, olhando para os cursos de licenciatura, tornase importante priorizar processos formativos aos futuros professores utilizando-se de pensamento fundamentado na "ecologia dos saberes" para além das crenças da "modernidade", composto por elementos ainda em transição da modernidade para a "pós-modernidade". Uma ecologia de saberes capaz de transgredir o paradigma da ciência moderna e o pensamento da anti subalternidade, capaz de imersão em práticas alternativas e valorativas às potencialidades entre as nações, passando, então, cada vez mais, a se fortalecer em ações internacionais ancoradas no processo de "compartilhamento da produção do conhecimento" e não mais na transferência do conhecimento. Esta perspectiva poderá contribuir para a formação de professores mais equitativos, fortalecidos no conhecimento científico, multicultural e internacional a serviço do fortalecimento das relações e interesses dos seus países com vida equitativa no global sul, tomando por base conhecimentos locais, regionais e interculturais indispensáveis para contribuir para a redução dos déficits produzidos pela ciência moderna e pelos processos de colonização até então vigentes. Tais conhecimentos da relação sul - sul ampliam-se na lógica da epistemologia 
do sul, pela capacidade de produção novos sentidos de organização societal e, consequentemente, de fortalecimento do conhecimento produzido nas nações do sul.

Outro elemento importante encontrado nos textos analisados, diz respeito que para os países do global sul, entre eles o Brasil, a internacionalização da Educação Superior tem íntima relação com a perspectiva de fluxos migratórios contemporâneos e da mobilidade dos estudantes via programas acadêmicos que fomentam e estimulam esse tipo de formação, considerando que a mobilidade da maioria dos estudantes é financiada por editais, acordos e por organismos (públicos e privados) de financiamento à graduação e pós-graduação. Além disso, é perceptível que a internacionalização da Educação Superior, nos países do hemisfério sul, ainda tem conotação com a circulação internacional de estudantes, a integração regional, o alargamento de fronteiras transnacionais e sua relação com a lógica do mercado, os acordos decorrentes de políticas nacionais e internacionais envolvendo a atuação e envolvimento dos países e suas Universidades, a exemplo dos países do Mercosul dos países PALOP.

A Figura 2 demonstra, em síntese, os principais elementos que balizam o cenário da internacionalização da Educação Superior:

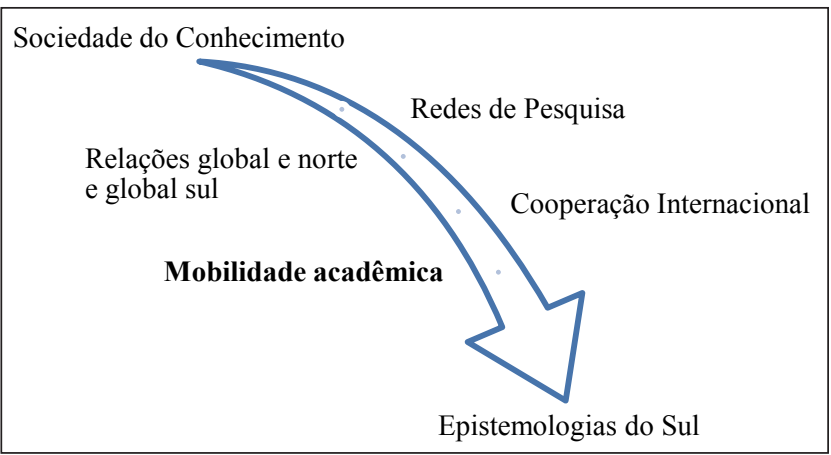

Figura 2. Configurações emergentes na internacionalização Fonte: Produzida pela autora. da Educação Superior no Brasil

Em síntese, esta figura retrata os principais elementos que indicam contextos emergentes à luz dos textos estudados, seja no que diz respeito ao conhecimento a ser trabalhado e produzido na formação dos futuros professores, quanto na [re]articulação de políticas públicas e definição/desenvolvimento de estratégias para a consolidação do fenômeno da internacionalização de maneira equitativa e solidária no contexto global.

\section{CONSIDERAÇÕES FINAIS}

Verificou-se que os contextos emergentes na perspectiva da internacionalização constituem-se desafios às IES e que a mobilidade acadêmica (discente e docente), na maioria dos trabalhos encontrados, ainda se mantém com uma forte característica nas estratégias institucionais, justamente porque, segundo os pesquisadores, potencializa a interlocução entre IES, entre múltiplas culturas e a produção de conhecimento entre os países e grupos de pesquisa.

Nos textos analisados, a terminologia "contextos emergentes" ainda é pouco discutida, o que demanda maior aprofundamento nos estudos conceituais e interrelações com elementos que caracterizam tais cenários na educação superior.

Entretanto, percebeu-se que tais indicativos de contextos emergentes, voltados à formação de professores, estão intimamente relacionados a elementos que interferem na produção de políticas educacionais, bem como são decorrentes de tais políticas e se descortinam em ações de governo e/ou institucionais a exemplo de cursos EAD e programas de governo mediatizados na dinamização curricular interna dos respectivos cursos. Além disso, é pontual a ampliação da interdependência entre Educação Básica e Superior, pautada em [re] articulações curriculares para a formação do cidadão global, bem como a necessidade do estabelecimento de acordos de cooperação e trabalho compartilhado entre as IES em nível mundial.

A lógica das epistemologias do sul vem com muita força demonstrar que os países do global sul tem, sim, elementos culturais que precisam ser valorizados e, sobretudo, utilizados nos currículos dos cursos de formação de professores para que esses balizem sua formação e atuação profissional valorizando o conhecimento multicultural e local.

Conclui-se que a universidade é o ponto de encontro da diversidade, e sendo um espaço diversificado e permeado por lutas pelo reconhecimento e pela valorização de todos os sujeitos, precisa, com base na educação voltada para a democracia e a cidadania, promover políticas públicas inclusivas de acesso e permanência a participação de todos/as independente de sua faixa etária, identidade de gênero, orientação sexual; origem étnico-racial, de suas condições econômicas, sociais, físicas e culturais.

Já, os resultados quanto a expansão da Educação Superior e os cursos de licenciatura, em sua importância e impacto por si só caracteriza-se como um contexto emergente. Entretanto, tal fenômeno evidencia-se em suas especificidades pela [re]articulação de espaços, tempos e metodologias administrativo-pedagógicas para as Instituições de Ensino Superior, bem como meios de acesso e permanência nos cursos de licenciatura devido expansão das unidades, vagas e cursos, assim como a diversificação do ensino pela modalidade a distância que vem se destacando com a finalidade de promover a democratização do ensino. 
Evidenciou-se, a partir das análises dos textos categorizados, convergências e também divergências entre as políticas públicas educacionais e os movimentos globais que delineiam o cenário e a conjuntura da Educação Superior na atualidade. Se de um lado, a Educação Superior vem vivendo intenso e diversificado processo de [re]significação, de outro ela passa a assumir uma lógica utilitarista no mercado de trabalho. Nessa conjuntura, os cursos de licenciatura são desafiados a reconhecer e compreender essas lógicas global/local e com a identificação e compreensão dos contextos emergentes na Educação Superior passam a reconhecer novos modos de estabelecer dinâmicas organizacionais que poderão impulsionar no desenvolvimento e organização do trabalho docente de qualidade.

\section{REFERÊNCIAS}

BARRETO, K. C. C. As cotas nos cursos de licenciatura presenciais da Universidade Federal de Goiás: a questão do reconhecimento. Dissertação de Mestrado. Universidade de Brasília (UNB), 2015. Disponível em: <https://sucupira.capes. gov.br/sucupira/public/consultas/coleta/trabalhoConclusao/ viewTrabalhoConclusao.jsf?popup=true\&id_trabalho $=2774200>$.

BDTD. Biblioteca Digital de Teses e dissertações. Disponível em: <http://www.ibict.br/informacao-para-ciencia-tecnologiae-inovacao $\% 20 /$ biblioteca-digital-Brasileira-de-teses-edissertacoes-bdtd $>$.

CAMATTI, L. A emergência do sujeito pedagógico surdo no espaço de convergência entre comunidade e escola de surdos. Dissertação (Mestrado) - Universidade Federal de Santa Maria, Santa Maria, 2011.

CAVALCANTI, L. B. Funcionamento e efetividade do laboratório virtual de ensino de matemática na formação de professores de matemática na modalidade EaD. Tese (Doutorado) - Universidade de Campinas, Campinas, 2014.

CERDEIRA, L.. Os desafios da gestão do ensino superior: algumas tendências e tensões. In: CUNHA, M. I.; BROILO, C. L. (Org.). Qualidade da educação superior: grupos investigativos internacionais em diálogo. Araraquara: Junqueira \& Marin, 2012.

COSTA, A. M. M. Educação para a cidadania e ensino superior. Dissertação (Mestrado) - Universidade Federal do Rio Grande do Norte, 2011.

DALLA NORA, D. O Trabalho Pedagógico no PIBID - Cultura Esportiva da Escola e suas repercussões para a formação inicial em Educação Física. Dissertação (Mestrado) - Universidade Federal de Santa Maria, Santa Maria, 2015. Disponível em: $<$ http://cascavel.ufsm.br/tede//tde_arquivos/48/ TDE-2016-02-18T113851Z-6882/Publico/DALLA\%20 NORA,\%20DAIANE.pdf $\$$.

FERREIRA, N. S. de A. As pesquisas denominadas "estado da arte". Revista Educação \& Sociedade, Campinas, n. 79, p. 257-272, ago. 2002.
FRANCO, M. E. D. P. MOROSINI, M. C. Qualidade na educação superior: dimensões e indicadores. Porto Alegre: EDIPUCRS, 2012.

FRANCO, L. I. A. Um caminho para a dança na educação física escolar: dinâmicas pautadas nos pilares básicos da educação/UNESCO. Dissertação (Mestrado) - Universidade Federal do Mato Grosso, 2015.

JAHN, A. B. O PIBID e a docência na educação física: perspectivas na formação inicial e continuada. Dissertação (Mestrado) - Universidade Federal do Rio Grande do Sul, 2015. Disponível em: <https://www.lume.ufrgs.br/bitstream/ handle/10183/139580/000990185.pdf? sequence=1>.

IBICT. Instituto Brasileiro de Informação em Ciência e Tecnologia. Disponível em: <http://bdtd.ibict.br/vufind $>$.

KNIGHT, J. Internationalization Remodelled: Definitions, Rationales and Approaches. Journal of Studies in International Education, 2012. Disponível em: <http://www.truworld.ca/ shared/assets/Internationalization-Remodeled29349.pdf>. Acesso em: 24 jun. 2016.

KENSKI, V. M. Tecnologias e tempo docente. Campinas, SP: Papirus, 2013.

LIMA, L. C.; AZEVEDO, M. N.; CATANI, A. M. O processo de Bolonha, a avaliação da educação superior e algumas considerações sobre a universidade nova. Avaliação, Campinas; Sorocaba, p. 7-36, v. 13, n. 1, mar. 2008.

LORENZET, D. Expansão e democratização da educação superior brasileira: a oferta de Licenciaturas nos Institutos Federais no estado do Rio Grande do Sul. Tese (Doutorado) Universidade Federal do Rio Grande do Sul, 2016. Disponível em: <http://www.lume.ufrgs.br/handle/10183/151686>.

MACIEL, D. A. S. Políticas públicas e democratização educacional: acesso e permanência no ensino superior através do Programa Reuni. Dissertação (Mestrado) Universidade Federal da Bahia, 2014. Disponível em: $<$ https://repositorio.ufba.br/ri/bitstream/ri/16465/1/A\%20 Disserta\%C3\%A7\%C3\%A30\%20-\%20Danilo\%20Alain\%20 Democratiza\%C3\%A7\%C3\%A30\%20Programa\%20REUNI. pdf $>$.

MONTEIRO, C. C. F. O ensino do design no Mercosul: uma proposta para a integração. 2013. 187 p. Tese (Doutorado em Desenho Industrial) - Universidade Estadual Paulista, Bauru, 2013.

MOROSINI, M. C. A universidade nos contextos emergentes: os modelos e papéis. In: FRANCO, M. E. D. P.; ZITKOSKI, J. J.; FRANCO, S. R. K. (Org.). Educação Superior e contextos emergentes. Porto Alegre: EDIPUCRS, 2016.

MOROSINI, M. C. Estado de conhecimento e questões do campo científico. Revista da Educação, Santa Maria, v. 40, n. 1, p. 101-116, jan.-abr. 2015.

MOROSINI, M. C. O Ensino Superior no Brasil. In: STEPHANOU, Maria; BASTOS, Maria Helena Câmara. Histórias e Memórias da Educação no Brasil. Petrópolis: Vozes, 2005. v. III: Século XX. p. 296-323.

MOROSINI, M. C. Qualidade da Educação Superior e contextos emergentes. Revista de Avaliação, Campinas; Sorocaba, v. 19, n. 2, p. 385-405, jul. 2014. 
MOROSINI, M. C.; FERNANDES, C. M. B. Estado do Conhecimento: conceitos, finalidades e interlocuções. Educação Por Escrito, v. 5, p. 154-164, 2014. Disponível em: <http:// revistaseletronicas.pucrs.br/ojs/index.php/porescrito/article/ view/18875>. Acesso em: 15 dez. 2016.

MOTTA, R. A. Tecnologia educacional no ensino superior: cenários da educação a distância e a avaliação institucional. In: COLOMBO, Sonia S. (Org.). Gestão universitária: os caminhos para a excelência. Porto Alegre: Penso, 2013.

NASCIMENTO, D. de S. A expansão da educação superior e o trabalho docente - um estudo sobre o Plano Nacional de Formação de Professores da Educação Básica (PARFOR) na UFPA. Dissertação (Mestrado) - Universidade Federal do Pará, 2012. Disponível em: <http://www.ppged.com.br/bv/arquivos/ File/dissertdenise.pdf $>$.

PIMENTA, S. G.; ANAStASIOU, L. G. C. Docência no Ensino Superior. 4. ed. São Paulo: Cortez, 2010.

PINHEIRO, J. C. Metamorfoses de formadores de professores na educação em ciências modificando práticas na prática de formação docente a distância. Tese (Doutorado) Universidade Federal do Pará, 2012.

PINTO, F. P. Análise das políticas de permanência: estudo multicaso das Universidades Federais do Estado de São Paulo. Dissertação (Mestrado) - Universidade Federal de São Paulo, 2015. Disponível em: <https://sucupira.capes. gov.br/sucupira/public/consultas/coleta/trabalhoConclusao/ viewTrabalhoConclusao.jsf?popup=true\&id_trabalho= $3234858>$.

SENA, A. P. de. Internacionalização da educação e formação de capital humano e cultural: estudo com alunos intercambistas da Universidade de Fortaleza (UNIFOR). Dissertação (Mestrado) - Universidade de Fortaleza, 2013. Disponível em: <http:// www.scirp.org/(S(1z5mqp453edsnp55rrgjct55))/reference/ ReferencesPapers.aspx?ReferenceID=1957405>.
SILVA, L. de O. Estágio supervisionado com uso de ambientes virtuais: possibilidades colaborativas. Tese (Doutorado) - Universidade Federal de Minas Gerais (UFMG), 2013. Disponível em: <http:/www.bibliotecadigital.ufmg.br/dspace/ handle/1843/MGSS-9DFDD2>.

STOLF, F. Assistência estudantil na Universidade Federal de Santa Catarina: uma análise inicial do Programa Bolsa Estudantil. Dissertação (Mestrado) - Universidade Federal de Santa Catarina, 2014. Disponível em: https://sucupira.capes. gov.br/sucupira/public/consultas/coleta/trabalhoConclusao/ viewTrabalhoConclusao.jsf?popup=true\&id_trabalho= $1607082>$.

TAVARES, M. Internacionalização da educação superior: estratégias e ações da Universidade Tecnológica Federal do Paraná. Dissertação (Mestrado) - Universidade Tecnológica Federal do Paraná, Campus Pato Branco (UTFPR), 2016. Disponível em: <http://repositorio.utfpr.edu.br/jspui/bitstream/1/1741/ 1/PB_PPGDR_M_Tavares\%2c\%20Marcelo_2016.pdf $>$.

TANAKA, E. M. A política de cotas para estudantes egressos de escolas públicas e a expansão da educação superior no Brasil: o PROUNI e o REUNI em foco. Dissertação de Mestrado. Universidade Estadual de Maringá (UNEM), 2013. Disponível em: https://sucupira.capes.gov.br/sucupira/public/ consultas/coleta/trabalhoConclusao/viewTrabalhoConclusao. jsf?popup=true \&id_trabalho $=663448$.

VICENTE, M. F. Programa Institucional de Bolsas de Iniciação à Docência - PIBID - e a formação inicial de professores. Dissertação (Mestrado) - Universidade Estadual Paulista, campus de Presidente Prudente, SP, 2016. Disponível em: <https://repositorio.unesp.br/bitstream/ handle/11449/136468/vicente_mf_me_prud.pdf? sequence $=3>$.

Recebido em 02-10-2017.

Aprovado em 30-12-2017. 